\title{
Association of Oral Disease with 12 Selected Variables: I. Periodontal Disease
}

\author{
CHESTER J. SUMMERS and ALBERT OBERMAN* \\ School of Dentistry and School of Public Health, The University of Michigan, Ann Arbor, \\ Michigan
}

The association of periodontal disease with 12 selected variables, considered to be intrinsic-systemic factors, was examined. A probability sample of 324 subjects, $\geq 20$ years old, was studied. The statistical analyses included simple, partial, and multiple correlations, and linear regression.

Systemic diseases in general, and coronary heart disease in particular, may be associated with periodontal disease. ${ }^{1-5}$ Most of the investigations that support this association, however, have involved small samples or a subjective classification for assessing periodontal disease. The purpose of this report is to examine the association of periodontal disease and 12 physiologic and social variables selected from measurements obtained during the initial investigation in the Tecumseh Community Health Study. ${ }^{6,7}$

Inflammatory periodontal lesions appear to be initiated by extrinsic-local factors that act on the gingival sulcus. These local factors may be calculus, oral debris, bacteria, overhanging fillings, occlusal imbalance, or even vigorous tooth brushing. There has been evidence pointing to bacteria as the most important of these factors. ${ }^{8}$ The inflammatory response, chronic in character, progresses to the underlying tissues as the irritants burrow to depth. This response, in turn, is modified by intrinsic-systemic conditions operative within the host. ${ }^{9}$ Generalized disease states must be considered as modifying rather than initiating factors. The associations between

This investigation was supported in part by USPHS Fellowship 1-F3-DE-34, 946-01 from the National Institute of Dental Research, and Fellowship 1-F3-HE-33, 537-01 from the National Heart Institute, National Institutes of Heaith, Bethesda, Md.

Received for publication November 8, 1967.

* Present Address: Department of Public Health and Epidemiology, The University of Alabama, Medical Center, Birmingham, Ala. age and periodontal disease $\mathrm{e}^{10-12}$ and between cigarette smoking and periodontal disease ${ }^{13-15}$ have been reported.

The individual with periodontal disease is usually treated by removing the extrinsiclocal factors. When the local factors are reduced, the observable evidence of disease regresses, even though the systemic factors remain the same. Periodontal disease may progress to residual damage (loss of the epithelial attachment) but, if the disease is treated, the gingival tissues can still return to normal.

Recent investigations ${ }^{16-20}$ have reported the association of certain variables with increased risk for coronary heart disease. These same studies have reported that multiple-risk variables further increase the risk of coronary heart disease compared with that incurred from single-risk variables alone. Because these variables have been known as precursors to coronary heart disease, the relationship of these variables to periodontal disease will be examined.

Extrinsic-local factors, calculus and plaque, have been previously shown to be strongly associated with periodontal disease, ${ }^{9}$ but were not considered because the focus of this report is to consider the intrinsic-systemic factors.

\section{Materials and Methods}

Since 1959, the schools of public health and medicine of The University of Michigan have conducted a longitudinal study of the health of the entire population of Tecumseh, Michigan, and the immediately surrounding area. ${ }^{7}$ As part of that investigation, complete medical histories were obtained and physical examinations, electrocardiograms, and selected laboratory tests were performed on the population of Tecumseh in 1959 and 1960. In addition, Jamison ${ }^{10}$ examined a 
$10 \%$ geographically stratified random sample (801 subjects) to determine the prevalence and severity of periodontal disease. Of those eligible for this study, 690 (86\%) participated.

The sample of the present report (408) consists of those subjects who were 20 years and older and for whom dental and medical information was available. Of the 408 subjects, 84 were edentulous and will be analyzed in a later report. ${ }^{21}$ The remaining 324 subjects (154 males and 170 females) were dentulous.

The 12 social and physiologic variables that seemed pertinent to the study were age, height, weight, relative weight, systolic blood pressure, diastolic blood pressure, blood glucose, serum cholesterol, serum uric acid, onesecond forced expiratory volume $\left(\mathrm{FEV}_{1}\right)$, alcohol consumption, and cigarette consumption.

The standard methods used for measurement of physiologic variables have been described previously. ${ }^{17,22}$ The rates of alcohol and cigarette consumption were obtained from the medical history. Alcohol was measured in units per week (one unit $=5 \mathrm{gm}$ of alcohol) and cigarette consumption was measured in packs per day.

The method used for assessing gingival disease was the periodontal disease index (PDI) described by Ramfjord. ${ }^{23}$ The PDI appears to be sensitive to residual damage. For example, using the PDI, a score of 4 or more (which indicates loss of epithelial attachment) cannot be reduced as the consequence of successful treatment. For this reason, the PDI score was used as a measure of periodontal assessment in this study.

Simple correlation analyses were performed for periodontal disease, as scored by the PDI, and each of the 12 variables. Because most of these variables were highly correlated with age, ${ }^{1 \bar{i}}$ a stepwise partial analysis and a multiple correlation analysis were performed with periodontal disease as the dependent variable. The stepwise partial correlation analysis proceeded in this manner:

(1) The dependent variable (periodontal disease) was preselected. (2) The independent variables were selected by order of magnitude; that is, by the highest partial correlation with the dependent variable. (3) After each

* The $\mathrm{FEV}_{1}$ is a measure of pulmonary obstruction and is used as an index of chronic obstructive lung disease. independent variable was selected, it was correlated with the dependent variable, with the effect of each preceding variable removed.

Because cigarette consumption and age were significantly related to PDI score in both sexes, further analysis of the variables was warranted. As a second experiment, (1) the subjects were divided by age and sex, and by nonsmokers and smokers. (2) to examine the association of periodontal disease and age, the effect of cigarette consumption related to both age and periodontal disease had to be held constant. The PDI adjusted score for smoking was computed by the following formula:

$$
\mathrm{PDI}_{\mathrm{adj}}=\frac{\mathrm{PDI}_{\mathrm{obs}}-\mathrm{PDI}_{\mathrm{pred}}}{\mathrm{pdi} \cdot \mathrm{sm}}=\frac{\mathrm{PDI}_{\mathrm{obs}}-(\overline{\mathrm{PDI}}+\mathrm{a}+\mathrm{bx})}{\mathrm{pdi} \cdot \mathrm{sm}}
$$

where

PDI $_{\text {ol: }}=$ observed PDI score

$\mathrm{PDI}_{\text {pred }}=$ predicted PDI score

$\widehat{\mathbf{P D}} \overline{\mathbf{I}}=$ mean PDI score

$\mathrm{a}+\mathrm{bx}=$ linear equation

$b=$ slope of the line

pdi $\cdot$ sm $=$ partial correlation coefficient for PDI score and smoking

\section{Results}

The results of simple correlations between periodontal disease, as scored by the PDI, and each of the 12 selected variables, according to sex, are presented (Table 1). The PDI score was significantly correlated (at the 0.05 level or better) with age, cigarette consumption, blood glucose, serum cholesterol, and $\mathrm{FEV}_{1}$ in both sexes. In females, however, the PDI score was also significantly correlated to height and to systolic and diastolic blood pressures. In males, the PDI score had the highest correlation coefficients with age, cigarette consumption, and $\mathrm{FEV}_{1}$; whereas, in females, the PDI score had the highest correlation coefficients with age, systolic blood pressure, and $\mathrm{FEV}_{1}$.

The results of the stepwise partial and multiple correlation analyses for the 12 variables, with periodontal disease as the dependent variable, are summarized according to sex (Table 2). In males, age had the highest correlation with periodontal disease; the partial correlation for this variable was the same as the simple correlation, because age had no variable preceding it. Cigarette consumption had the next highest partial correlation with periodontal disease; the partial correlation for the variable was determined by 
TABLE 1

Simple Correlations Between PDi Score and 12 Selected Variables, According to Sex

\begin{tabular}{lccccc}
\hline \hline & \multicolumn{2}{c}{ Male } & & \multicolumn{2}{c}{ Female } \\
\cline { 2 - 3 } \cline { 6 - 7 } \multicolumn{1}{c}{ Variable } & $\begin{array}{c}\text { Simple } \\
\text { Correlation } \\
\text { Coefficient }\end{array}$ & $\begin{array}{c}\text { Significance } \\
\text { Level }\end{array}$ & & $\begin{array}{c}\text { Simple } \\
\text { Correlation }\end{array}$ & $\begin{array}{c}\text { Significance } \\
\text { Cevel }\end{array}$ \\
\hline Age & 0.507 & 0.01 & & 0.512 & 0.01 \\
Height & -0.129 & NS* & & -0.149 & 0.05 \\
Weight & -0.078 & NS & & 0.013 & NS \\
Relative weight & 0.082 & NS & & -0.032 & NS \\
Systolic blood pressure & 0.023 & NS & & 0.349 & 0.01 \\
Diastolic blood pressure & 0.094 & NS & & 0.185 & 0.05 \\
Blood glucose & 0.246 & 0.01 & & 0.240 & 0.01 \\
Serum cholesterol & 0.181 & 0.05 & & 0.224 & 0.01 \\
Serum uric acid & -0.065 & NS & & 0.109 & NS \\
FEV & -0.300 & 0.01 & & -0.424 & 0.01 \\
Alcohol consumption & 0.060 & NS & & 0.028 & NS \\
Cigarette consumption & 0.302 & 0.01 & & 0.176 & 0.05 \\
\hline
\end{tabular}

* Not significant.

TABLE 2

Partial and Multiple Correlation Analyses for 12 Independent Variables, with Periodontal Disease Index (PDI) Score as the Dependent Variable, According to Sex

\begin{tabular}{|c|c|c|c|c|c|}
\hline Step & $\begin{array}{c}\text { Independent Variable } \\
\text { Eliminated }\end{array}$ & $\begin{array}{c}\text { Partial } \\
\text { Correlation } \\
\text { Coefficient }\end{array}$ & $\begin{array}{l}\text { Multiple } \\
\text { Correlation } \\
\text { Coefficient }\end{array}$ & $\begin{array}{c}\text { Reduction } \\
\text { of the Total } \\
\text { Variance } \\
\text { Explained }\end{array}$ & $P$ \\
\hline \multicolumn{6}{|l|}{ Males } \\
\hline 1 & Age & 0.507 & 0.507 & 0.686 & $<0.01$ \\
\hline 2 & Cigarette consumption & 0.354 & 0.591 & 0.936 & $<0.01$ \\
\hline$\overline{3}$ & Blood glucose & 0.144 & 0.603 & 0.972 & 0.07 \\
\hline 4 & Weight & -0.103 & 0.608 & 0.990 & 0.20 \\
\hline 5 & Serum uric acid & -0.046 & 0.610 & 0.994 & 0.57 \\
\hline 6 & Height & -0.032 & 0.610 & 0.996 & 0.69 \\
\hline 7 & Cholesterol & -0.029 & 0.611 & 0.997 & 0.71 \\
\hline 8 & Systolic blood pressure & -0.021 & 0.611 & 0.998 & 0.79 \\
\hline 9 & Diastolic blood pressure & 0.027 & 0.611 & 0.999 & 0.74 \\
\hline 10 & Relative weight & 0.006 & 0.611 & 0.999 & 0.94 \\
\hline 11 & $\mathrm{FEV}_{1}$ & 0.006 & 0.611 & 0.999 & 0.94 \\
\hline 12 & Alcohol consumption & -0.005 & 0.611 & 1.000 & 0.94 \\
\hline \multicolumn{6}{|c|}{ Females } \\
\hline 1 & Age & 0.512 & 0.512 & 0.718 & $<0.01$ \\
\hline 2 & Cigarette consumption & 0.239 & 0.551 & 0.835 & $<0.01$ \\
\hline 3 & Systolic blood pressure & 0.190 & 0.574 & 0.904 & 0.01 \\
\hline 4 & $\mathrm{FEV}_{1}$ & -0.154 & 0.588 & 0.948 & 0.04 \\
\hline 5 & Relative weight & -0.112 & 0.594 & 0.970 & 0.14 \\
\hline 6 & Diastolic blood pressure & -0.083 & 0.598 & 0.983 & 0.28 \\
\hline 7 & Cholesterol & -0.065 & 0.601 & 0.990 & 0.40 \\
\hline 8 & Weight & -0.051 & 0.602 & 0.995 & 0.51 \\
\hline 9 & Alcohol consumption & -0.034 & 0.603 & 0.997 & 0.66 \\
\hline 10 & Blood glucose & -0.029 & 0.603 & 0.999 & 0.70 \\
\hline 11 & Serum uric acid & 0.023 & 0.603 & 0.999 & 0.77 \\
\hline 12 & Height & $<0.001$ & 0.603 & 1.000 & 0.99 \\
\hline
\end{tabular}

holding constant the preceding variable, age. Blood glucose had the next highest partial correlation with PDI score; the partial correlation for this variable was determined by holding constant the preceding variables, age and cigarette consumption.

The multiple correlation coefficients were determined in the same manner. The values for "Reduction of the Total Variance Ex- plained" (Table 2) are cumulative and indicate how much of the variance that can be explained is accounted for by each independent variable, including the previous variable.

Inspection of Table 2 reveals that, for both sexes, age and cigarette consumption had the highest partial correlations as well as $P$ values of less than 0.01 . In the males, the partial correlation for age was very high, and for 
cigarette consumption was high; these two variables accounted for $94 \%$ of the explained variance. The partial correlation coefficients of the remaining ten variables, for males, were not statistically significant, even though the simple correlation coefficients of some of these variables were significant.

In the female subjects, the partial correlation for age was very high, and for cigarette consumption was high; these two variables accounted for $83 \%$ of the explained variance. In females, the partial correlation coefficients of systolic blood pressure and of $\mathrm{FEV}_{1}$ also were significant.

Cigarette consumption. - The mean PDI scores for the groups that were created are shown (Fig 1). In all age groups for both

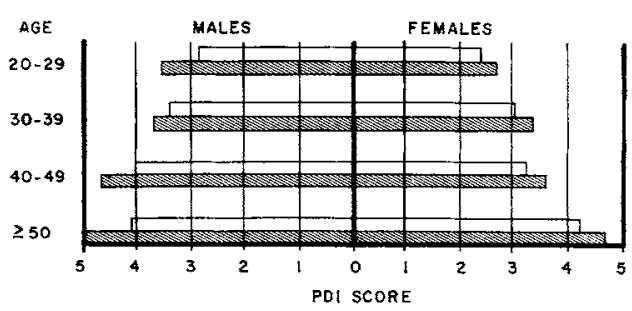

FIG 1.-Mean periodontal disease index (PDI) score according to age, sex, and smoking. White bars, nonsmokers; grey bars, smokers.

sexes, the smokers had a higher average PDI score than the nonsmokers. In the age groups 40 to 49 and $>50$ for males, the difference was statistically significant at the 0.01 and 0.05 levels, respectively.

AGE.-The adjusted PDI scores for smokers and unadjusted PDI scores for nonsmokers were used to compute regression lines for periodontal disease and age for both sexes.

$$
\begin{aligned}
& \text { PDI }=\mathrm{a}+(\mathrm{b})(\mathrm{x}) \\
& \text { Male smokers }=3.3944+(0.0560) \\
& \text { Male nonsmokers }=3.5109+(0.0431)(\text { age-39.113) } \\
& \text { Female smokers }=3.0740+(0.0431)(\text { age-39.937) } \\
& \text { Female nonsmokers }=3.2603+(0.0433)(\text { age-36.985) } \\
&(\text { age-40.138) }
\end{aligned}
$$

These regression lines were plotted in Figure 2. As age increased, PDI score increased for both sexes, and for nonsmokers as well as for smokers. At all ages, males had higher PDI scores than females. The slopes $(b)$ of the regression lines for all females and male

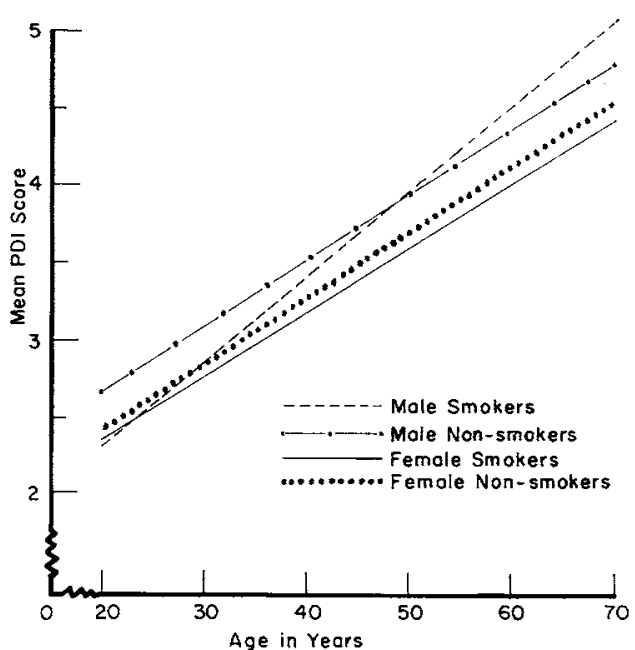

FIG 2.- Regression line for mean periodontal disease index (PDI) score and age, according to sex and smoking. Adjusted PDI scores for smokers and unadjusted PDI scores for nonsmokers.

nonsmokers were the same. The slope of the regression line for male smokers was greater than those for the other groups, but not significant $(P=0.11)$.

\section{Discussion}

At times, a simple correlation coefficient between two variables may be significant, although these two variables may also be associated with a third variable. Partial correlation analysis can remove the effect of this third variable. The data presented showed high correlations between PDI score and many of the 12 selected variables; partial correlation analysis removed the effects of the third variable common to the remaining variables.

Periodontal disease was more severe in the smokers for each age group. Cigarette consumption may affect periodontal disease in two ways. Directly, smoking can act as a source of gingival irritation (local factor); indirectly, smoking has been linked to systemic illnesses, such as coronary heart disease, ${ }^{24}$ which can affect the gingival tissue response $^{4}$ (systemic factor) through alterations to vascular tissue and through hemodynamics. However, smokers and nonsmokers may have different oral hygiene habits, or smokers and nonsmokers may be different in constitution, with the smokers 
having a predisposition to gingival irritation.

When the effect of cigarette consumption related to both age and periodontal disease was held constant, the slope for male smokers was greater than that for the male nonsmokers and both groups of females. This finding may indicate (1) an age-smoking interaction, unaccounted for by the adjustment for smoking, (2) unrecognized qualitative differences between male smokers and the rest of the sample, or (3) both of these possibilities. Smoking, implicated in the pathogenesis of several diseases including coronary heart disease, appears to be associated with periodontal disease, independent of age.

The relative percentage of male smokers (59\%) was higher than that of female smokers $(40 \%)$; the mean amount of cigarettes consumed by males ( 1.17 packs/day) was higher than for females ( 0.72 packs day). These two factors may account for the lack of differences between the female nonsmokers and female smokers.

Speculation on the underlying relations between periodontal disease and the variables studied is limited by sample size and the cross-sectional approach. The Tecumseh Community Health Study is an ongoing study that will yield longitudinal data bearing on the reported associations. Such data may substantiate the findings of the present investigation and permit inferences about cause and effect.

The PDI represents a cumulative and irreversible score when loss of epithelial attachment occurs. A hazard always exists when associating a cumulative score with a current habit or condition that may not have been in effect during the time the irreversible condition occurred. Nevertheless, a strong association has been demonstrated between the PDI and other indexes and measurements based on present and active periodontal dissease.

Smoking, a known risk factor in coronary heart disease, appears to be associated with periodontal disease, independent of age.

\section{Conclusions}

The association of periodontal disease with 12 selected variables, known to influence the risk of certain medical diseases and considered to act as intrinsic-systemic factors, was examined. The data represented measurements taken from a $10 \%$ probability sample ( 324 subjects 20 years old or more) as part of the Tecumseh Community Health Study. Periodontal disease was assessed by the periodontal disease index (PDI).

The males had higher PDI scores than females. The PDI scores correlated with age, cigarette consumption, blood glucose, serum cholesterol, and $\mathrm{FEV}_{1}$ in both sexes. With a stepwise partial correlation analysis wherein age was held constant, cigarette consumption, systolic blood pressure, and $\mathrm{FEV}_{1}$ significantly correlated with PDI score in females. Only cigarette consumption was significantly correlated with PDI score in males. In all age groups for both sexes, smokers had higher PDI scores than did nonsmokers.

Analysis by linear regression showed that the slope for male smokers was greater than the slope for the male nonsmokers and both groups of females when the effect of cigarette consumption related to both age and periodontal disease was held constant.

These results confirm findings from previous studies (in selected populations) and suggest that the relationship between periodontal disease and certain physiologic and social variables might be worthy of longitudinal study.

The dental data were collected by Homer C. Jamison; the medical data are reported for the research staff of the Cardiovascular Research Center, The University of Michigan (Thomas Francis, Jr., director).

\section{References}

1. Burket, L.W.: Systemic Aspect of Periodontal Disease, J Periodont 24:7-15, 1953.

2. STAhL, S.S., and Fox, L.M.: Histologic Changes of the Oral Mucosa Associated with Certain Chronic Diseases, Oral Surg 6:339-343, 1953.

3. SANDlER, H.C., and STAHL, S.S.: The Influence of Generalized Disease on Clinical Manifestations of Periodontal Disease, $J$ Amer Dent Assoc 49:665-667, 1954.

4. Sandler, H.C., and STAHL, S.S.: Prevalence of Periodontal Disease in a Hospitalized Population, J Dent Res 39:439-448, 1960.

5. WIENER, S.P.; WARD, H.L.; and ARCHER, M.: The Rate of Deposit of Supragingival Calculus as an Indicator of Individuals Prone to Coronary Heart Disease: A Preliminary Report, J Chronic Dis 17:191-198, 1964.

6. NAPIER, J.A.: Field Methods and Response Rates in the Tecumseh Community Health Study, Amer J Public Health 52:208-216, 1962. 
7. Francis, T., JR, and Epstein, F.H.: Tecumseh, Michigan, Milbank Mem Fand Quar 43:333-342, 1965.

8. Carranzo, F.A.: "Review of the Literature on Periodontal Pathology," in RAMFJorD, S.P.; KeRR, D.A.; and AsH, M.M. (eds.): World Workshop in Periodontics, Ann Arbor: University of Michigan, 1966.

9. STAHL, S.S.: "The Etiology of Periodontal Disease; An Appraisal of Current Literature," in RAMFJORD, S.P.; KERR, D.A.; and AsH, M.M. (eds.): World Workshop in Periodontics, Ann Arbor: University of Michigan, 1966.

10. JAMISON, H.C.: Prevalence and Severity of Periodontal Disease in a Sample of a Population, thesis, University of Michigan School of Public Health, Ann Arbor, 1960.

11. Russell, A.L.: International Nutrition Surveys: A Summary of Preliminary Dental Findings, J Dent Res 42:233-244, 1963.

12. Periodontal Disease in Adults: United States 1960-1962, publication 1000, series 11, No. 12, National Center for Health Statistics, US Public Health Service, 1965.

13. ARno, A.; Schei, O.; Lovdal, A.; and Waerhaug, J.: Alveolar Bone Loss as a Function of Tobacco Consumption, Acta Odont Scand 17:3-8, 1959.

14. Brantzaeg, P., and Jamison, H.C.: A Study of Periodontal Health and Oral Hygiene in Norwegian Army Recruits, J Periodont 35:302-307, 1964.

15. Pindborg, J.J.: Tobacco and Gingivitis: II. Correlation Between Consumption of Tobacco, Ulceromembranous Gingivitis and Calculus, J Dent Res 28:460-463, 1949.

16. Doyle, J.T.; Heslin, S.; Hilleboe, H.E.; and FormeL, P.F.: Early Diagnosis of
Ischaemic Heart Disease, New Eng $J$ Med 261:1096-1101, 1959.

17. Epstein, F.H.; Francis, T., Jr.; Hayner, N.S.; Johnson, B.C.; KJElsBERG, M.O.; NAPIer, J.A.; Ostrander, L.D., JR.; Payne, M.W.; and DODGE, H.J.: Prevalence of Chronic Diseases in Distribution of Selected Physiological Variables and Pathological States in a Total Community, Tecumseh, Michigan, Amer $J$ Epidem 81: 307-322, 1965

18. Epstein, F.H.: Epidemiology of Atherosclerosis, presented at the Symposium on Heart Disease, San Francisco, Calif, Sept 28-30, 1966.

19. Kagan, A.; Kannel, W.B.; Dawber, T.R.; and Revotskie, N.: The Coronary Profile, Ann NY Acad Sci 97:883-894, 1963.

20. Paul, O.; Lepper, M.H.; Phelan, W.H.; Dupertuis, G.W.; MacMillan, A.; McKEAN, H.; and PARK, H.: A Longitudinal Study of Coronary Heart Disease, Circulation 28:20-31, 1963.

21. Summers, C.J., and Oberman, A.: The Association of Oral Disease and 12 Selected Variables: II. Edentulism, $J$ Dent Res 47, 1968 , to be published.

22. Tecumseh Community Health Study: Statistical Tables: Means, Standard Deviations, Ranges and Selected Percentiles for 15 Variables by Age and Sex, mimeo, University of Michigan, School of Public Health, Ann Arbor, 1960.

23. RAMFJORD, S.P.: Indices for Incidence and Prevalence of Periodontal Disease, $J$ Periodont 30:51-59, 1959.

24. Doyle, J.T.: Etiology of Coronary Disease: Risk Factors Influencing Coronary Disease, Mod Conc Cardiov Dis 25:1-6, 1966. 